\title{
Synthesis of Polymer Composites with Luminescent Properties ${ }^{\dagger}$
}

\author{
Mateusz Gargol * and Beata Podkościelna \\ Department of Polymer Chemistry, Institute of Chemical Sciences, Faculty of Chemistry, \\ Maria Curie-Sklodowska University, Maria Curie-Skłodowska Sq. 5, 20-400 Lublin, Poland; \\ beatapod@poczta.umcs.lublin.pl \\ * Correspondence: gargol.mateusz@poczta.umcs.lublin.pl \\ † Presented at 1st International Electronic Conference on Applied Sciences, 10-30 November 2020; \\ Available online: https://asec2020.sciforum.net/.
}

Published: 9 November 2020

\begin{abstract}
This paper presents the synthesis and characterization of new polymeric materials in the form of composites with a luminescent filler using the photopolymerization methodology. In the synthesis of the composites, bisphenol A glycerolate ( 1 glycerol/phenol) diacrylate was used as a main monomer, whereas methyl methacrylate, N-vinyl-2-pyrrolidone, and 2-hydroxyethyl methacrylate were applied as reactive diluents. In the role of photoluminescent dopant, a previously synthesized photoluminescent copolymer, N-vinyl-2-pyrrolidone witch 2,7-(2-hydroxy-3-methacryloyloxypropoxy) naphthalene, was used. The compositions were prepared with an increasing amount of filler: $0,0.5$, $1,2,5,10 \mathrm{wt} \%$. As a result of the performed syntheses, 18 new compositions were obtained which generated green-yellow light after excitation by UV radiation. The influence of the increasing luminescent filler content on the selected properties of the composites was evaluated. The thermal and mechanical behaviors of the composites were determined by means of differential scanning calorimetry (DSC) and Shore D hardness. Moreover, the chemical structures of the polymeric materials were confirmed by the attenuated total reflectance Fourier transform infrared spectroscopy (ATR/FT-IR) method. These results show that the incorporation of the photoluminescent copolymer into polymeric compositions can be method for obtaining functional materials for the production of special polymeric coatings or for the production of optical fiber sensors.
\end{abstract}

Keywords: UV polymerization; polymer composites; photoluminescence

\section{Introduction}

Numerous substances and materials with luminescence properties are found in chemistry. Their amount increases due to the demand for more specific, effective, and resistant polymeric materials. This group of luminescent polymer materials includes, among others, coordination polymers (CPs). They are an important group of materials owing to their diverse crystal structures and extensive application, such as in gas adsorption/separation, heterogeneous catalysis, luminescent probe, drug delivery, magnetism, guest/ion-exchange, and catalysis [1-6]. Trivalent rare earth elements (lanthanides), similar to other selected metals and their metal organic frameworks (MOFs), are characterized by good photoactive properties - e.g., a broad emission region or color intensity. These features of MOFs contribute to a great variety of applications in lighting or optical devices (displays, lasers, optical fibers) and biomedical equipment (medical diagnosis) [7,8]. Unfortunately, these materials are quite expensive due to the poor accessibility of rare earth elements.

Nowadays stimuli-responsive organic luminescent materials are attracting more and more attention from scientists and are providing new possibilities for application. Exposed to different stimuli, these materials exhibit fluorescent properties [9-12]. Volatile organic compounds are one of 
the causes of air pollution issues which have promoted studies on metal organic frameworks which can be used for sensing environmental pollutants based on color changes [13-16]. Photochromic substances based on organic compounds attract much attention owing to their optical property applications-for example, in displays, security inks, optical recording, or sensors $[17,18]$. Photochromic CPs are constructed using, among other things, naphthalene diimides (NDIs), which possess luminescent properties and are chemically robust $[19,20]$. Easily processable fluorescent polymers based on naphthalene due to their intense fluorescence and good thermo-chemical stabilities can be used for the production of polymer light-emitting diodes, laser dyes, and fiber optic sensors [21-23].

The aim of this study was to obtain new resistant polymeric composites with photoluminescent properties using the photopolymerization method and their detailed characterization.

\section{Materials and Methods}

\subsection{Materials}

N-vinyl-2-pyrrolidone (NVP) (Fluka), methyl methacrylate (MMA) (Sigma Aldrich), and 2hydroxyethyl methacrylate (HEMA) (Fluka) were used as active solvents and bisphenol A glycerolate ( 1 glycerol/ phenol) diacrylate (Bis.GDA) (Sigma Aldrich) was used as a main monomer in the synthesis of the composites. 2,2-dimetoxy-2-phenylacetophenone (Irqacure ${ }^{\circledR} 651$ ) (Fluka) was added to these mixtures as a photoinitiator of UV polymerization. As a photoluminescent filler, the powdered copolymer of N-vinyl-2-pyrrolidone with the 2,7-(hydroxy-3-metha-cryloyloxypropoxy) naphthalene (2,7-NAF.DM) form was applied, whose synthesis is detailed elsewhere [24].

\subsection{Methods}

The ATR-FT/IR spectra were obtained with a Bruker TENSOR 27 FTIR spectrophotometer (Germany). They were recorded from 4000 to $600 \mathrm{~cm}^{-1}$ an average of 32 scans with a resolution of 4 $\mathrm{cm}^{-1}$ in the transmittance mode. The DSC thermograms were obtained with the use of a Netzsch 204 calorimeter (Germany). The $10.0 \pm 0.05 \mathrm{mg}$ samples were placed in the aluminum pans with pierced lids, whereas an empty aluminum crucible with a pierced lid was used as a reference. Dynamic scans were performed in the temperature range from 25 to $600{ }^{\circ} \mathrm{C}$ in the nitrogen atmosphere with a flow rate of $10 \mathrm{~mL} / \mathrm{min}$. The hardness of the analyzed samples was measured using a Shore D method using a Zwick 7206/H04 hardness apparatus (Germany) at $25^{\circ} \mathrm{C}$. Three measurements were made for all the composites and the average values were calculated.

\subsection{Composites Preparation}

The method of composites synthesis was based on radical polymerization. The process of sample preparation proceeded in several stages. Bisphenol A glycerolate (1 glycerol/phenol) diacrylate (Bis.GDA) was heated in a laboratory dryer to $60^{\circ} \mathrm{C}$ and then an appropriate amount was weighed and placed in a glass vessel. Next, the calculated amount of MMA was transferred to Bis.GDA and thoroughly mixed. The ratio of Bis.GDA to active solvent was 7:3 in all the samples. The weighed amount of the photoluminescent filler was put into the mixture in small portions (while still mixing). Next, the $1 \mathrm{wt} . \%$. of UV-initiator (2,2-dimethoxy-2-phenylacetophenone) was added. Finally, the whole content was moved into a special glass form and irradiated with UV light for 30 minutes [25]. As a result, a composite (with dimensions: $8 \mathrm{~cm}$ width and $12 \mathrm{~cm}$ of length) was obtained. The same procedure was repeated for the samples with NVP and HEMA as solvents. Finally, in this way 18 samples were synthesized with a thickness of $4 \mathrm{~mm}( \pm 0.1 \mathrm{~mm})$. The experimental parameters of the synthesis are collected in Table 1 . The chemical structures of the monomers and composites are presented in Figure 1. 
Table 1. Composition of the polymeric composites containing 2,7-NAF.DM-NVP (the copolymer of $\mathrm{N}$-vinyl-2-pyrrolidone with the 2,7-(hydroxy-3-methacryloyloxypropoxy)naphthalene).

\begin{tabular}{lcccc}
\hline \multicolumn{1}{c}{ Type of Sample } & $\begin{array}{c}\text { Amount of } \\
\text { Bis.GDA (g) }\end{array}$ & $\begin{array}{c}\text { Amount of } \\
\text { Active Solvent }\end{array}$ & $\begin{array}{c}\text { Amount of } \\
\text { Irgaqure }^{\circledR} \text { 651 }\end{array}$ & $\begin{array}{c}\text { Amount of 2,7- } \\
\text { NAF.DM-NVP }\end{array}$ \\
\hline 0\% wt. 2,7-NAF.DM-NVP & $10 \mathrm{~g}$ & $4.28 \mathrm{~g}$ & $0.14 \mathrm{~g}$ & $0 \mathrm{~g}$ \\
0.5\% wt. 2,7-NAF.DM-NVP & $10 \mathrm{~g}$ & $4.28 \mathrm{~g}$ & $0.14 \mathrm{~g}$ & $0.07 \mathrm{~g}$ \\
1\% wt. 2,7-NAF.DM-NVP & $10 \mathrm{~g}$ & $4.28 \mathrm{~g}$ & $0.14 \mathrm{~g}$ & $0.14 \mathrm{~g}$ \\
2\% wt. 2,7-NAF.DM-NVP & $10 \mathrm{~g}$ & $4.28 \mathrm{~g}$ & $0.14 \mathrm{~g}$ & $0.29 \mathrm{~g}$ \\
$5 \%$ wt. 2,7-NAF.DM-NVP & $10 \mathrm{~g}$ & $4.28 \mathrm{~g}$ & $0.14 \mathrm{~g}$ & $0.76 \mathrm{~g}$ \\
10\% wt. 2,7-NAF.DM-NVP & $10 \mathrm{~g}$ & $4.28 \mathrm{~g}$ & $0.14 \mathrm{~g}$ & $1.60 \mathrm{~g}$ \\
\hline
\end{tabular}

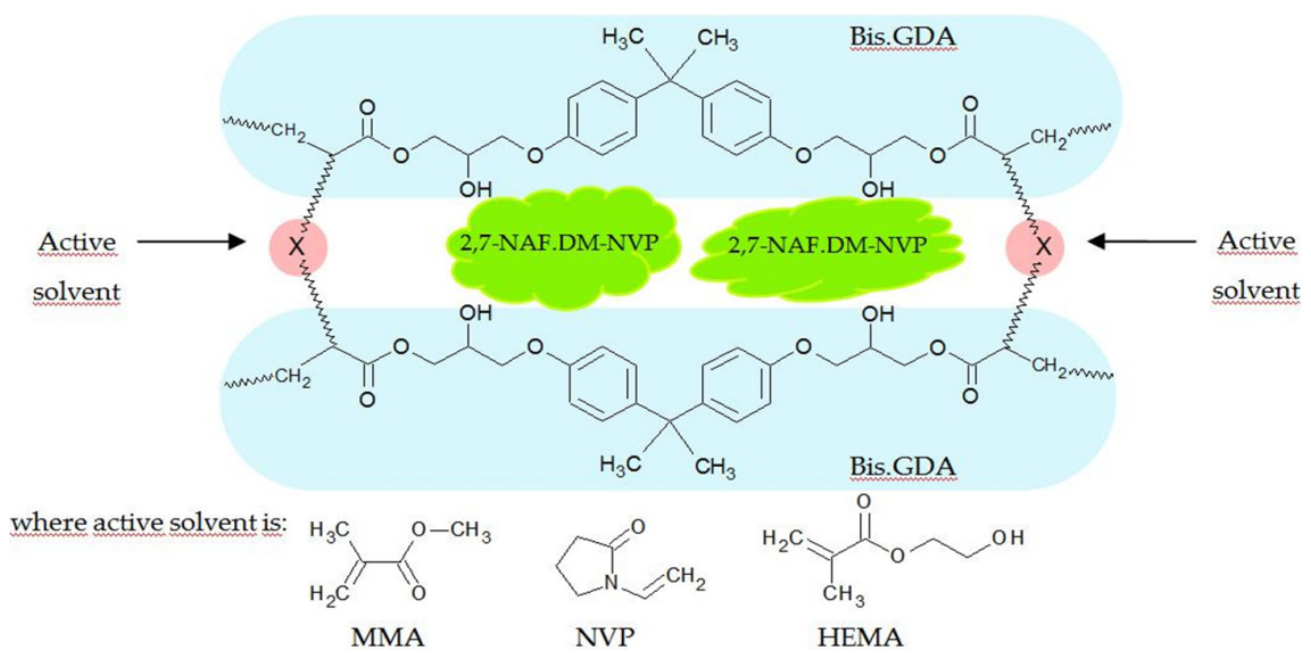

Figure 1. Simplified structure of the polymer composite with the derivative photoluminescent filler of naphthalene-2,7-diol.

\section{Results}

\subsection{Attenuated Total Reflectance-Fourier Transform Infrared Spectroscopy (ATR-FTIR)}

Characteristic bands of the functional groups are visible on the FT-IR/ATR spectra (Figure 2). The courses of the spectra were similar due to the fact that the main components of these materials are Bis.GDA and NVP, which is evidenced by the presence of characteristic bands of appropriate functional groups. FT-IR $\left(\mathrm{cm}^{-1}\right)$ of the photoluminescent composites: 2964-2950 and 2875-2874 (asymmetric and symmetric $\mathrm{C}-\mathrm{H}$ stretching of $\mathrm{CH}_{2}$ and $\mathrm{CH}_{3}$, respectively); 1725-1722 $\mathrm{cm}^{-1}$ (stretching vibrations of $\mathrm{C}=\mathrm{O}$ groups which is characteristic of acrylates); 1610 and $1509 \mathrm{~cm}^{-1}$ (aromatic $\mathrm{C}=\mathrm{C}$ symmetric and asymmetric stretching vibrations); $1450-1425 \mathrm{~cm}^{-1}$ (deformation vibrations of methyl and methylene groups); $1242-1241$ and $1040-1039 \mathrm{~cm}^{-1}$ (stretching vibrations of C-O bonds in alkylaryl and aromatic groups, respectively); $1181-1180 \mathrm{~cm}^{-1}$ (stretching vibrations of ester group C-O-C); $828-826 \mathrm{~cm}^{-1}$ (deformation vibrations of Ar and Ar-H).
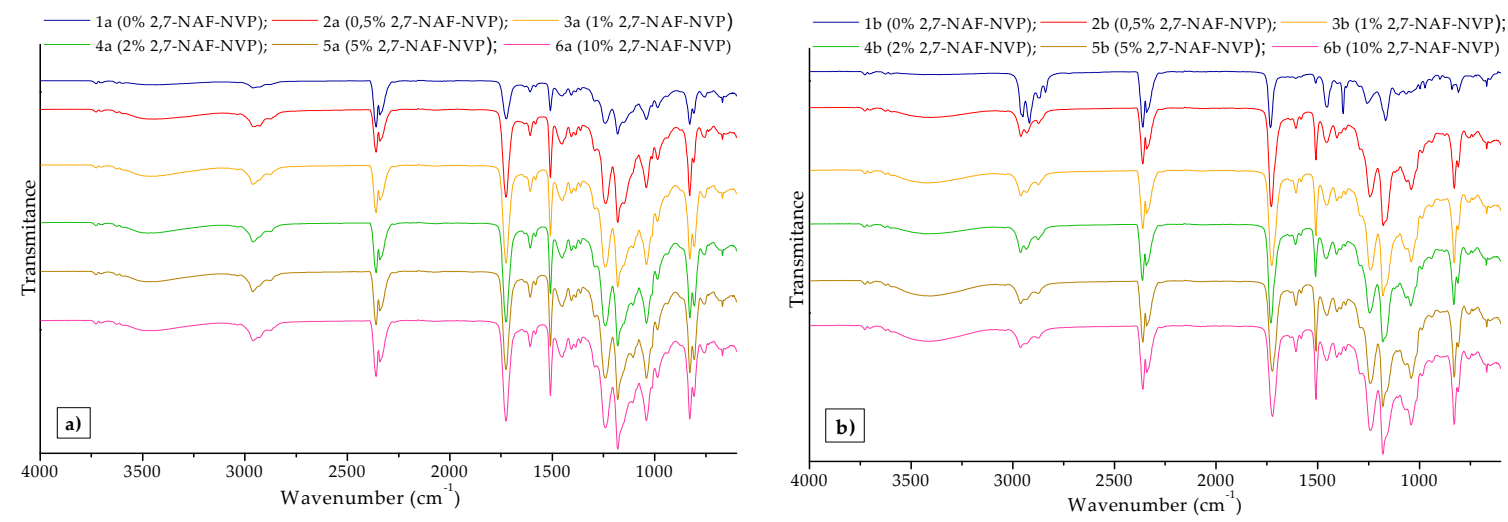


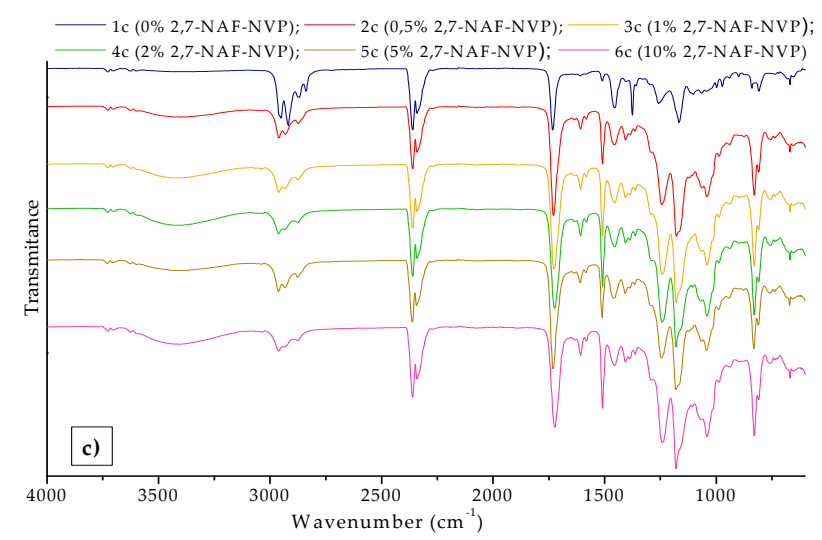

Figure 2. ATR/FT-IR spectra of the composites: (a) samples with MMA (methyl methacrylate), (b) with NVP (N-vinyl-2-pyrrolidone), and (c) with HEMA (2-hydroxyethyl methacrylate).

\subsection{Differential Scanning Calorimetry (DSC)}

The DSC analyses show some similarities in the thermal behavior of the obtained materials. It can be seen that, for six chosen composites, a change in the filler content of the sample has no significant effect on the shape of the DSC curves (Figure 3). Table 2 contains numerical data determined from the DSC curves after the heating cycles. Comparing the obtained results, a clear endothermic effect connected with the maximum degradation of the samples is visible. The values of $\mathrm{T}_{\max }$ temperatures are in the range of $390.1-413.1{ }^{\circ} \mathrm{C}$. Besides this, on all curves one see a small endothermic peak $\left(\mathrm{T}_{1}\right)$ at a temperature between 60.4 and $81.2^{\circ} \mathrm{C}$. This effect is probably a result of the evaporation of small amounts of unreacted monomers. For the studied samples, no exothermic effects occur during heating.

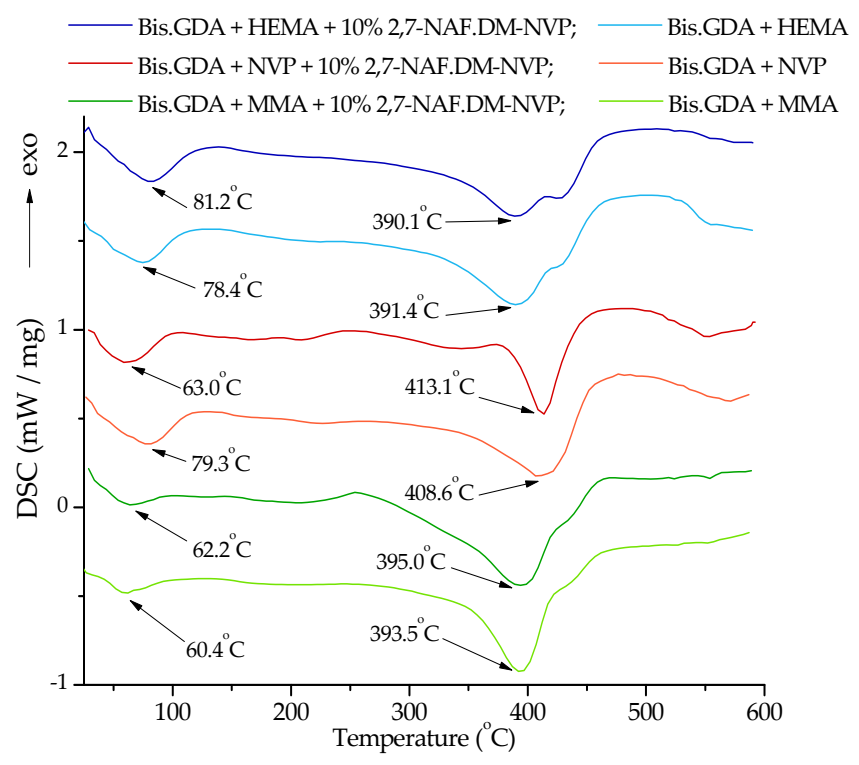

Figure 3. DSC curves of the six selected samples.

Table 2. DSC curves of the six selected composite samples.

\begin{tabular}{lcc}
\hline \multicolumn{1}{c}{ Type of Sample } & $\mathbf{T}_{\mathbf{1}}$ & $\mathbf{T}_{\max }$ \\
\hline 1a (Bis.GDA + MMA) & 60.4 & 393.5 \\
6a (Bis.GDA + MMA + 10\% 2,7-NAF.DM-NVP) & 62.2 & 395.0 \\
1b (Bis.GDA + NVP) & 79.3 & 408.6 \\
6b (Bis.GDA + NVP + 10\% 2,7-NAF-NVP.DM-NVP) & 63.0 & 413.1 \\
1c (Bis.GDA + HEMA) & 78.4 & 391.4 \\
6c (Bis.GDA + HEMA + 10\% 2,7-NAF.DM-NVP) & 81.2 & 391.5 \\
\hline
\end{tabular}




\subsection{Hardness Measurements}

The values of hardness were expressed in the D scale and are presented in Figure 4. The hardness of the samples was in the range from 64.3 to 73.3 units.

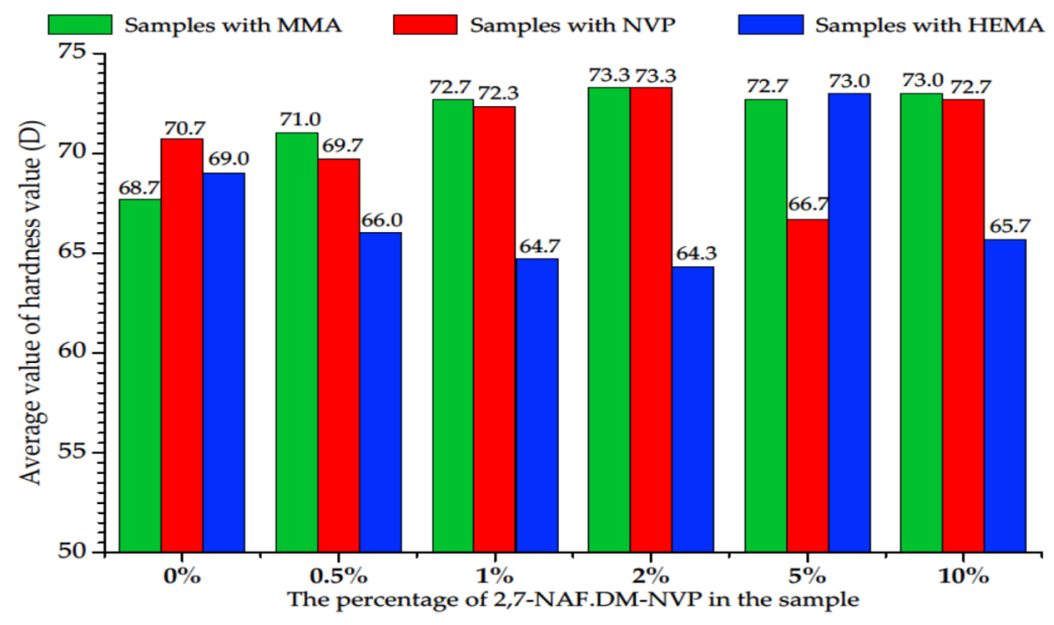

Figure 4. Hardness diagram of the obtained composites.

The above results show that the amount of luminescent dopant in the NVP and MMA samples increases the hardness of the synthesized materials slightly. This parameter is comparable for individual series of composites. The hardness values show slight changes with the type of solvent used. The results for the composites with NVP improved slightly compared to those with HEMA. The highest values of hardness were recorded for the materials with the MMA.

\section{Conclusions}

This article discusses the synthesis of the new polymeric composites with luminescent properties. Crosslinking monomer bisphenol A glycerolate diacrylate and three different active solvents: MMA, NVP, and HEMA were applied for synthesis of new materials through UV polymerization. The copolymer of methacrylic derivative of naphtaleno-2,7-diol with NVP was used as a photoluminescent composite filler in different amounts $(0,0.5,1,2,5$, and $10 \mathrm{wt}$. $\%)$. The ATR/FTIR analysis confirms the proper course of the polymerization reaction. The spectra show the peaks derived from characteristic fragments, such as the methyl and methylene groups, aromatic rings, and ether and carbonyl groups. The data obtained during the DSC analysis confirm that the amount of dopant used does not affect the thermal properties of the samples. The materials were characterized by similar parameters of thermal stability. Based on the hardness tests, it can be concluded that the type of solvent used results in different values of hardness (the samples with MMA are statistically the hardest). The resulting composites emit yellow-green light under the influence of UV radiation.

\section{References}

1. Lustig, W.P.; Mukherjee, S.; Rudd, N.D.; Desai, A.V.; Li, J.; Ghosh, S.K. Metaleorganic frameworks: Functional luminescent and photonic materials for sensing applications, Chem. Soc. Rev. 2017, 46, 32423285.

2. Chowdhuri, A.R.; Laha, D.; Chandra, S.; Karmakar, P.; Sahu, S.K. Synthesis of multifunctional upconversion $\mathrm{NMOFs}$ for targeted antitumor drug delivery and imaging in triple negative breast cancer cells. Chem. Eng. J. 2017, 319, 200-211.

3. Konstantatos, A.; Sørensen, M.A.; Bendix, J.; Weihe, H. Lanthanide coordination complexes framed by sodium ions: Slow relaxation of the magnetization in the Dy(III) derivative. Dalton Trans. 2017, 46, 60246030 .

4. Shen, N.N.; Cai, M.L.; Song, Y.; Wang, Z.P.; Huang, F.Q.; Li, J.R.; Huang, X.Y. Supramolecular Organization of $\left[\mathrm{TeCl}_{6}\right]^{2-}$ with Ionic Liquid Cations: Studies on the Electrical Conductivity and Luminescent Properties. Inorg. Chem. 2018, 57, 528-5291. 
5. Parmar, B.; Patel, P.; Murali, V.; Rachuri, Y.; Kureshy, R.; Khan, N.; Suresh, E. Efficient Heterogeneous Catalysis by Dual Ligand $\mathrm{Zn}(\mathrm{II}) / \mathrm{Cd}(\mathrm{II}) \mathrm{MOF}$ for Knoevenagel Condensation Reaction: Adaptable Synthetic Routes, Characterization, Crystal Structure and Luminescence Studies. Inorg. Chem. Front. 2018, 5, 2630-2640.

6. Aulsebrook, M.L.; Biswas, S.; Leaver, F.M.; Grace, M.R.; Graham, B.; Barrios, A.M.; Tuck, K.L. A luminogenic lanthanide-based probe for the highly selective detection of nanomolar sulfide levels in aqueous samples, Chem. Commun. 2017, 53, 4911-4914.

7. Zhu, X.J.; Su, Q.Q.; Feng, W.; Li, F.Y. Anti-Stokes shift luminescent materials for bioapplications. Chem. Soc. Rev. 2017, 46, 1025-1039.

8. Heine, J.; Müller-Buschbaum, K. Engineering metal-based luminescence in coordination polymers and metal-organic frameworks. Chem. Soc. Rev. 2013, 42, 9232-9242.

9. Chen, S.; Wenxuan, W.; Jia, Q.; Meng, Y.; Wang, K.P.; Hu, Z.Q. Dimethylamino naphthalene-based cyanostyrene derivatives with stimuli responsive luminescent properties. Dyes Pigm. 2019, 171, 1-7.

10. Zhang, Y.; Yu, J.; Bomba, H.N.; Zhu, Y.; Gu, Z. Mechanical force-Triggered drug delivery. Chem. Rev. 2016, 116, 12536-12563.

11. Zhang, C.; Sun, L.; Yan, Y.; Shi, H.; Wang, B.; Liang, Z.; Li, J. A novel photo- and hydrochromic europium metal-organic framework with good anion sensing properties. J. Mater. Chem. C 2017, 5, 8999-9004.

12. Medishetty, R.; Zaręba, J.K.; Mayer, D.; Samoc, M.; Fischer, R.A. Nonlinear optical properties, upconversion and lasing in metal-organic frameworks, Chem. Soc. Rev. 2017, 46, 4976-5004.

13. Wang, X.Q.; Feng, D.D.; Zhao, Y.D.; Fang, D.D.; Tang, J.; Fang, L.M.; Yang, J. A multifunctional 1D Cdbased metal-organic complex for the highly luminescent sensitive detection of $\mathrm{Fe}^{3+}, \mathrm{CrO}_{4}{ }^{2-} / \mathrm{Cr}_{2} \mathrm{O}_{7}{ }^{2-}$, and nitroaromatic explosives. J. Solid State Chem. 2019, 274, 40-46.

14. Kamal, M.S.; Razzak, S.A.; Hossain, M.M. Catalytic oxidation of volatile organic compounds (VOCs) - A review. Atmos. Environ. 2016, 140, 117-134.

15. Bobbitt, N.S.; Mendonca, M.L.; Howarth, A.J.; Islamoglu, T.; Hupp, J.T.; Farha, O.K.; Snurr, R.Q. Metalorganic frameworks for the removal of toxic industrial chemicals and chemical warfare agents. Chem. Soc. Rev. 2017, 46, 3357-3385.

16. Qiao, X.; Chen, X.; Huang, C.; Li, A.; Li, X.; Lu, Z.; Wang, T. Detection of exhaled volatile organic compounds improved by hollow nanocages of layered double hydroxide on Ag nanowires. Angew. Chem. Int. Ed. 2019, 131, 16675-16679.

17. Pacheco-Liñán, P.J.; Fernández-Sainz, J.; Bravo, I.; Garzón-Ruiz, A.; Alonso-Moreno, C.; CarrilloHermosilla, F.; Antiñolo, A.; Albaladejo, J. Guanidine substitutions in naphthyl systems to allow a controlled excited-state intermolecular proton transfer: Tuning photophysical properties in aqueous solution. J. Phys. Chem. C 2018, 122, 9363-9373.

18. Wang, M.S.; Yang, C.; Wang, G.E.; Xu, G.; Lv, X.Y.; Xu, Z.N.; Lin, R.G.; Cai, L.Z.; Guo, G.C. A roomtemperature X-ray-induced photochromic material for X-ray detection. Angew. Chem. Int. Ed. 2012, 51, 3432-3435.

19. Pan, M.; Lin, X.M.; Li, G.B.; Su, C.Y. Progress in the study of metaleorganic materials applying naphthalene diimide (NDI) ligands. Coord. Chem. Rev. 2011, 255, 1921-1936.

20. Liu, T.; Chen, Y.; Sun, Z.L.; Liu, J.; Liu, J.J. Switchable luminescent properties in two photochromic naphthalene diimide coordination networks. J. Solid State Chem. 2019, 277, 216-220.

21. Podkościelna, B.; Lipke, A.; Gawdzik, B.; Majdan, M. Synthesis, characterization and luminescent properties of new copolymers of dimethacrylate derivatives of naphthalene-2,7-diol. Polym. Adv. Technol. 2015, 26, 176-181.

22. Ahn, T. Systematic approaches for blue light-emitting polymers by introducing various naphthalene linkages into carbazole containing PPV derivatives. Trans. Electr. Electron. Mater. 2013, 14, 258-262.

23. Mori, T.; Kijima, M. Synthesis and electroluminescence properties of carbazole-containing 2,6naphthalene-based conjugated polymers. Eur. Polym. J. 2009, 45, 1149-1157.

24. Podkościelna, B.; Gawdzik, B. Influence of diluents compositions on the porous structure of methacrylate derivatives of aromatic diols and divinylbenzene. Appl. Surf. Sci.2010, 256, 2462-2467. 
25. Gargol, M.; Podkościelna, B. The use of waste materials as fillers on polimer composites-Synthesis and thermal properties. Physicochem. Probl. Miner. Process. 2019, 55, 1551-1557.

Publisher's Note: MDPI stays neutral with regard to jurisdictional claims in published maps and institutional affiliations.

(c)

(C) 2020 by the authors. Licensee MDPI, Basel, Switzerland. This article is an open access article distributed under the terms and conditions of the Creative Commons Attribution (CC BY) license (http://creativecommons.org/licenses/by/4.0/). 